\title{
Bilateral internal carotid artery occlusion secondary to closed head injuries
}

\author{
DAVID YASHON, ${ }^{1}$ A. B. JOHNSON, II, AND JOHN A. JANE \\ From the Department of Neurology and Neurological Surgery, University of Illinois, \\ College of Medicine, and Presbyterian-St. Luke's Hospital, Chicago, Illinois
}

Complications of basilar skull fracture, such as carotid cavernous fistulae, meningitis, cerebrospinal fluid rhinorrhoea and otorrhoea, pneumatocele, and various cranial nerve disturbances, are well known (Gurdjian and Webster, 1958). In addition, unilateral thrombosis of the internal carotid artery, both with and without basilar skull fracture, has frequently been reported after closed head and neck injury (Ecker, 1945; Higazi, 1963, Hockaday, 1959; Murray, 1957; Northcroft and Morgan, 1944; Schneider and Lemmen, 1952). Bilateral occlusion of the internal carotid arteries as a cause of death secondary to basilar skull fracture has apparently not been reported. This presentation demonstrates pre- and post-mortem documentation of a case of bilateral internal carotid occlusion in the carotid siphon secondary to fracture of the cranial base.

\section{CASE PRESENTATION}

This 25-year-old man, who had previously been in good health, sustained severe trauma to the head and trunk when the car in which he was a passenger struck an expressway viaduct at high speed. The patient was seated in the right front seat. He was seen in the emergency room one hour after the accident.

Upon examination the patient was comatose. Blood pressure was $70 / 50 \mathrm{~mm}$. $\mathrm{Hg}$, pulse was 110 . There was no blood in the external auditory canal or nares. Numerous ecchymoses and abrasions were present over the trunk and forehead but there were no open wounds. The carotid arteries were palpable and equal in the neck. The chest was clear to percussion and auscultation. Heart sounds were normal The abdomen was 'doughy' and slightly distended. Bowel sounds were present but hypoactive. No abdominal masses were present. Neurological examination revealed fixed, dilated pupils bilaterally. The patient responded to no external stimuli. Reflexes were hypoactive but present. The sign of Babinski was present bilaterally.

Haematocrit was 52 ; white blood count was 11,850 . Urine analysis, including microscopic examination, was normal.

Spontaneous respirations ceased upon admission to the

${ }^{1}$ Address: 912 S. Wood Street, Chicago, Illinois 60612. emergency room. Endotracheal intubation and continuous positive pressure respiratory assistance were then immediately instituted. Bilateral carotid angiography was performed using the Sanchez-Perez seriograph. Films were taken at 0.7 second intervals for seven seconds. Angiography revealed bilateral internal carotid artery occlusion in the carotid siphon (Figures 1 and 2). No fracture was evident on these films. Consciousness was never regained, and in spite of all efforts (including whole blood, tracheostomy, vasopressors, hypothermia, and steroids), the patient expired 18 hours after admission.

\section{POST-MORTEM EXAMINATION}

The body was that of a well-developed male, weighing $180 \mathrm{lb}$. Several cutaneous abrasions and ecchymoses were present. The right pleural cavity contained $500 \mathrm{ml}$. of blood. The source of this bleeding was intercostal vessels which had been torn, secondary to a fracture of the tenth rib. The left pleural cavity contained $1,000 \mathrm{ml}$. of blood which was due to rupture of several small blood vessels in the wall of the thorax. The abdominal cavity contained some $500 \mathrm{ml}$. of blood secondary to small lacerations of the spleen and liver. The lungs were atelectatic and showed early minimal bronchopneumonia.

The brain weighed $1,450 \mathrm{~g}$. and was minimally ecchymotic, appeared swollen throughout, and the gyri were flattened. The brain was rather soft in consistency. The base of the brain and left convexity were covered with $25 \mathrm{ml}$. of clotted blood. No abnormality of the cerebellum or brain-stem was noted. There was no evidence of cerebral herniations. The vertebral-basilar system of vessels was entirely intact. Examination of the vault revealed a fracture of the base through both the left and right petrous ridges extending to the sella turcica through both lacerated foramina (Figure 3).

The following study was carried out to substantiate further the diagnosis of bilaterally occluded internal carotid arteries. The common carotid arteries were ligated high in the thorax and with the external carotids occluded, the internal carotid arteries were injected using a no. 18 needle and a $20 \mathrm{ml}$. syringe. Under high manual pressure, no flow could be obtained from the right internal carotid as seen from the cranial base at the foramen lacerum. When the left carotid was similarly injected, a small amount of clot was ejected intracranially after some pressure was brought to bear. Flow was then easily 


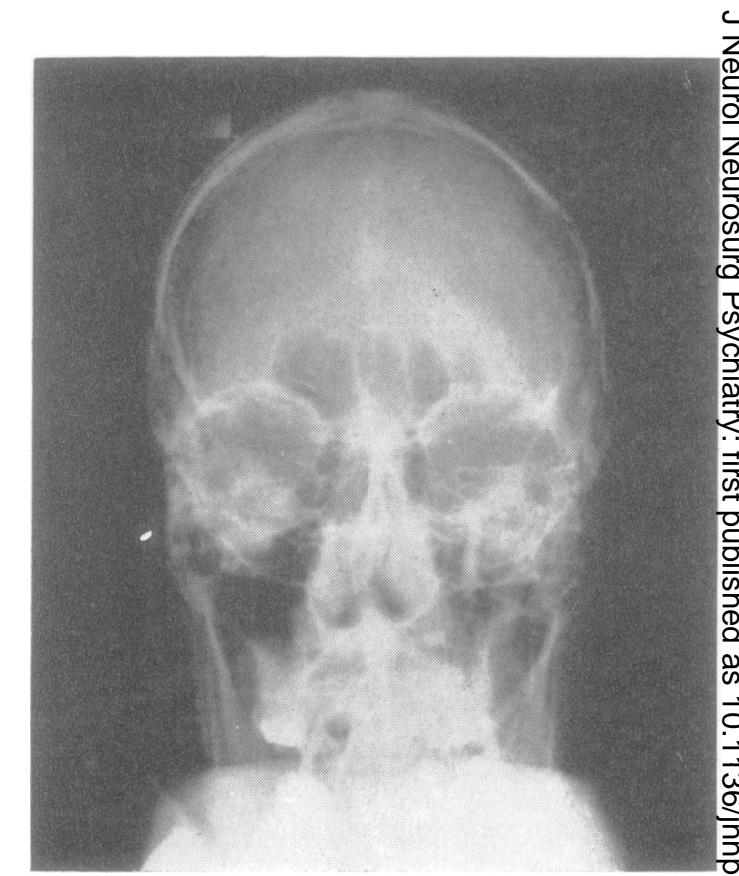

FIG. 2. Left carotid injection demonstrating total occluj sion. Representative film of antero-posterior seriograplis series.

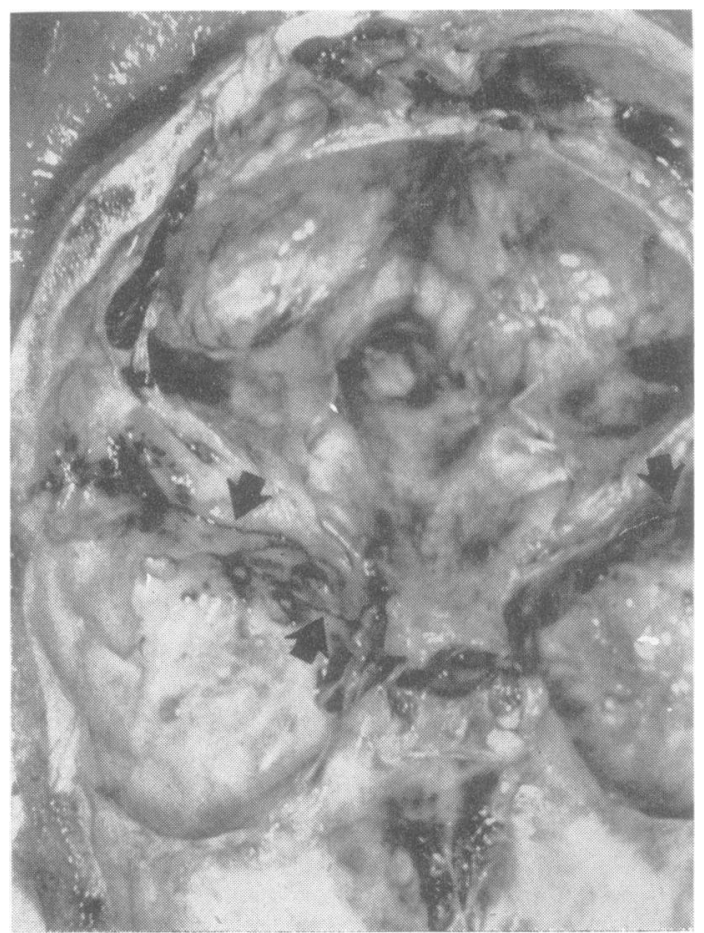

FIG. 3. series.

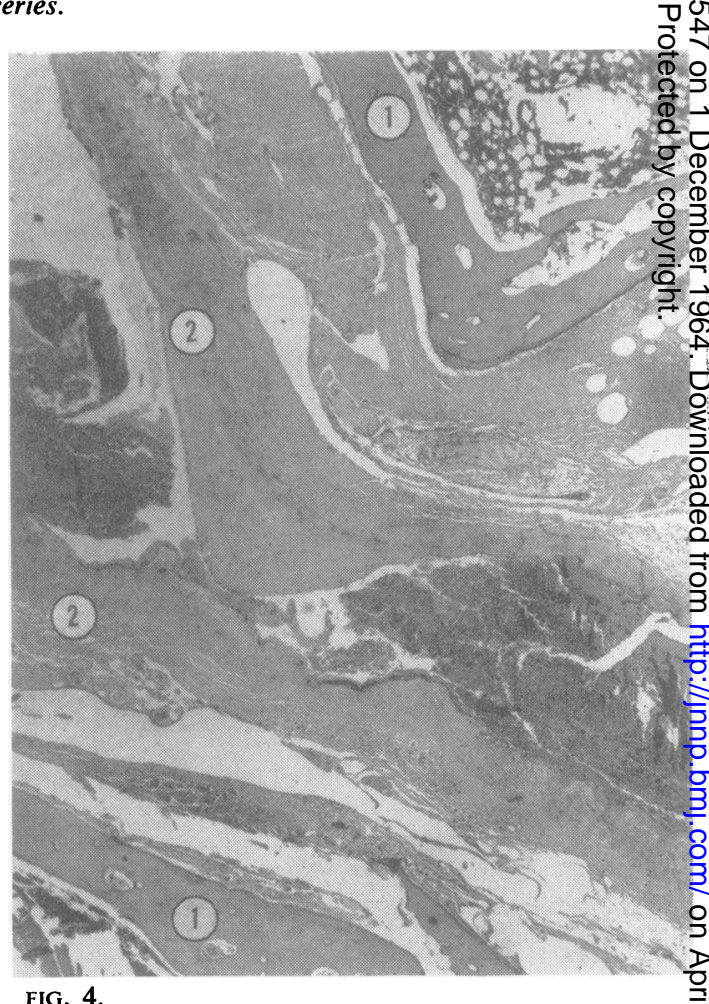

FIG. 4.
FIG. 1. Right carotid injection demonstrating total occlusion. Representative film of antero-posterior seriograph

FIG. 3. Bipetrous fracture of cranial base (slightly retouched). Arrows point to fracture line.

FIG. 4. Site of bony occlusion of right carotid artery in petrous portion of temporal bone. Example of horizontat sections of carotid artery taken serially. The vessel (2) is impinged between bony spicules (1) on either side. The contents of the vessel consist of premortem thrombus and haemorrhage. 
obtained. It appeared, therefore, both from the arteriographic and post-mortem evidence, that the occlusion had occurred in the petrous portion (Gray and Goss, 1954; Bull and Schunk, 1962) of the internal carotid artery bilaterally. The occlusion was perhaps somewhat higher on the right. The petrous portion of the base of the skull, including the sella turcica and both foramina lacerum, were removed in toto and decalcified.

Coronal sections of the brain after fixation revealed the white matter to be somewhat swollen. There were no areas of infarction or softenings visible grossly.

Microscopic examination of the brain and decalcified internal carotid arteries was performed. The meningeal vessels were congested and the subarachnoid space displayed areas of recent haemorrhage. The brain itself showed some areas of recent microscopic focal haemorrhage but none of these were present in sections taken of the brain-stem. Increased capillary vascularity was present in the forebrain but no area of frank necrosis was present. There was one area of softening in which compound granular corpuscles were prominent. In this area polymorphonuclear leucocytes were minimal. Sections were taken through the involved carotid arteries after decalcification. Both of these showed minimal atherosclerotic changes with calcification. They were surrounded by patches of closely packed erythrocytes. This apparently was due to haemorrhage which had occurred in the perivascular areas. The right internal carotid artery was seen to be occluded by a bony bar (Figure 4). On serial sectioning of this area, the occlusion was traced to patent areas, both superior and inferior. The left internal carotid was also studied. At no point was an adventitial breach seen. Attached to the intimal layer, in several sections, was an area of recent ante-mortem thrombosis but the vessel was by no means occluded. The occlusion on the left, which was demonstrable angiographically and grossly at necropsy, was attributed to direct haemorrhagic and soft tissue impingement of the vessel in the carotid canal. Spasm and partial internal thrombosis may have been factors also. The right carotid artery was occluded by bony fragments and was directly attributable to the fracture.

\section{DISCUSSION}

Cerebral injuries are said to be open or closed depending on whether or not there is a breach of the dura (Blackwood, McMenemey, Meyer, Norman, and Russell, 1963). This case report demonstrates an unusual cause of death in closed head injury, and heretofore has not been reported. However, a similar traumatic bipetrous fracture with unilateral thronbosis, which also resulted in death, has been reported by Löhr (1936). Other cases of unilateral thrombosis of the internal carotid artery secondary to basilar skull fracture have been reported (Ecker, 1945; Sedzimir, 1955). Brass (1957) reported a case of disruption of the basilar artery with haemorrhage secondary to indirect trauma. A small fracture in the roof of the orbit was thought to be unimportant. No other fracture was resent. He attributed rupture of the artery to torsion. In addition, there are other reports (Greco, 1935; Murray, 1957; Verneuil, 1872) in which intimal and medial damage is implicated as a cause for carotid occlusion after closed head and neck injury (in the absence of a basilar skull fracture) in spite of the fact that there was no sign of damage to the adventitial layer of the artery. Torsion during trauma is held responsible for the disruption in these cases also.

Recently, two cases of traumatic unilateral occlusion of the internal carotid artery, secondary to closed indirect trauma and similar to those cases described above, have been treated by direct surgical intervention and evacuation of thrombus (Houck, Jackson, Odom, and Young, 1964). In one case the occlusion was in the area of the bifurcation of the common carotid. The second was higher in the cervical area. These authors state that 15 similar cases were found in a review of the literature. None were treated by direct evacuation of the thrombus. Of the 15 patients, only seven survived and neurological sequelae in the survivors were formidable.

Signs or symptoms after major intracranial or extracranial vessel occlusion are dependent on the quality and quantity of collateral vasculature. Acute traumatic occlusion of a single internal carotid artery is compatible with life (Houck et al., 1964). Major or minor neurological signs may be present depending mostly on the state of the collateral circulation and associated damage to the central nervous system. Acute unilateral carotid occlusion is also practised surgically in cases of carotid cavernous fistulae and certain intracranial aneurysms. Few sequelae are observed. In our case, acute bilateral occlusion was not compatible with life, but other factors may have been involved.

The potential efficacy of anastomosis to the central nervous system can be judged from Doniger's (1963) report in which complete bilateral occlusion of the internal carotid arteries and complete occlusion of the basilar artery was verified angiographically in a 48 year-old woman. Neurological deficit was minimal. The aetiology of the obstructive disease was presumably arteriosclerosis. Collateral circulation was maintained via the ophthalmic arteries and posterior inferior cerebellar arteries. Major intracerebral vessels were noted to fill in a retrograde manner. Manual compression of either common carotid artery failed to produce further deficit. Dr. Blackwood mentions another case (1963) in which sufficient blood reached the brain through only one internal carotid artery, the other three major vessels being occluded by arteriosclerosis.

Spontaneous, usually atherosclerotic but often idiopathic (Silverstein and Hollin, 1963), unilateral 
occlusion has been frequently reported (Ameli and Ashby, 1949; Andrell, 1943; Johnson and Walker, 1951) and is seen often in vascular disease practice. It is usually, of itself, compatible with life and may cause a spectrum varying from no neurological signs to a major neurological deficit. Bilateral spontaneous occlusion has also been reported (Fields, Edwards, and Crawford, 1961; Frøvig, 1946; Groch, Hurwitz, and McDowell, 1960). This type of occlusion is also compatible with life and neurological deficit may be minimal although most cases result in death. This syndrome, occurring in young people, has been attributed to thromboangiitis obliterans (Frøvig, 1946). Recently, 17 patients, all under age 40, with carotid occlusion, were studied (Humphrey and Newton, 1960). In only two of these cases was the cause due to trauma. In addition, the authors accumulated 107 further cases from the literature. These patients also were under the age of 40 and had internal carotid artery occlusion. Twenty-two of the cases were due to trauma. In no case was a basilar skull fracture noted, and in no case was occlusion bilaterally noted. The categories into which these patients were placed were recent head injury, past head injury, penetrating injuries of the palate and pharynx, and wounds or contusions of the neck.

The indication for angiography in acute head injury varies from centre to centre. Avoidance of false angiographic localization of the site of internal carotid artery occlusion has been stressed (Murphey and Shillito, 1959). This hazard may be obviated by obtaining films on a rapid changing device and by obtaining delayed films for at least six seconds after completion of the injection. Had not angiography been performed in our case, it is not difficult to see that the primary pathology in this case might have been overlooked.

As mentioned earlier, angiographic non-visualization of the internal carotid and other vessels has been reported frequently with blunt, non-penetrating trauma to the head and neck. The fact that this obstruction was reversible in at least one report (Verbiest and Calliauw, 1959) suggests that spasm may be a contributing factor in this type of arterial occlusion. Spasm could conceivably later result in thrombosis. Intracranial arterial spasm is a frequent occurrence in the presence of ruptured intracranial aneurysm so that in severe trauma its existence is entirely feasible. A syndrome has been previously presented (Ecker, 1945) in which spasm of the internal carotid artery is considered to be due to relatively mild trauma to the internal carotid artery. The common denominator in these cases was thought to be the application of force and traction to this vessel, resulting in spasm and subsequent dysfunction of a cerebral hemisphere, the brain swelling in the acute phase, narrowing of the cerebral arteries, and unis lateral ventricular dilatation in the later stages Further cases have been presented (Fotopulos? 1962: Schneider and Lemmen, 1952) in which uniso lateral thrombosis of the internal carotid artery secondary to non-penetrating injuries, simulated epidural or subdural haematomata both in clinical. course and in the contrast study investigation. The presence of increased intracranial pressure as manifest by papilloedema, shift of the midline structures and increased cerebrospinal fluid pressure, as ascero tained by lumbar puncture, is well recognizedo (Caldwell and Hadden, 1948; Elvidge and Werner, 1951; Verbiest and Calliauw, 1959) occurring with $\mathbb{D}$ thrombosis of the carotid artery following trauma. D

An anatomical point may be discussed briefly here. Anatomists (Gray and Goss, 1954; Kecht, 1937) have divided the internal carotid artery into cervical, petrous, cavernous, and cerebral portions. $\omega$ We are concerned in this case with bilateral obstruction of the second (petrous) portion of the artery.0 This portion begins when the internal carotid artery enters the base of skull in the carotid canal in theo petrous portion of the temporal bone. It then may tre divided into ascending, 'knee', and horizontal limßs. It lies at first in front of the cochlea and tympaminc cavity and is separated from the latter by a thin bo 1 lamina. The entire carotid canal within the petrogs portion measures between $25 \mathrm{~mm}$. and $35 \mathrm{~mm}$. in length (Kecht, 1937). The petrous portion terminats at the entrance of the artery into the cranium at tred foramen lacerum. It is here that the artery lies in thecarotid sulcus and that the cavernous portion of theo artery begins. It is here at the junction of the petrous. and cavernous portions that the artery is mosto vulnerable, since the thickness of the bone over the air cells of the sphenoid sinus in the carotid sulcuso may be as little as $0.5 \mathrm{~mm}$. (Kecht, 1937). Even minorô trauma in these areas could cause a basilar skull $\varrho$ fracture and go unnoticed on routine skull radio- $\overrightarrow{\overrightarrow{0}}$ graphs, which is by far the more common situation. 3 The result might be severance of the vessel (carotid $\bar{F}$ cavernous fistula) or, less commonly, occlusion as in? the present case. With occlusion in this area, retrograde thrombosis might lead to the mistaken? diagnosis of occlusion in the neck, thereby account-:int for certain cases of mysterious internal carotid 3 . cervical thrombosis.

The present case might be regarded as an example of acute bilateral occlusion of the carotid systemo with patent collateral and vertebral-basilar systems. Major vessel occlusion was studied as early as 1836 吾 by Cooper (1836). Andreyev (1935) has shown that $50 \%$ to $60 \%$ of dogs will survive permanent bi- $/$ lateral occlusion of both common carotid and verte- $N$ 
bral arteries. Forty per cent of survivors exhibited no demonstrable neurological sequelae. Total cerebral ischaemia has been produced experimentally in the dog (Boyd and Connolly, 1962). Due to a very large collateral reservoir, this is a difficult experimental model to produce. It was found that the dog will tolerate up to eight minutes of total cerebral ischaemia without evidence of permanent brain damage. Total cerebral ischaemia of nine minutes or more will produce severe permanent brain damage or immediate death in the dog. Gardner (1935) found no permanent neurological deficits in monkeys after simultaneous unilateral ligation of the vertebral, common carotid, and internal and external carotid arteries. However, after such a ligation, ligation of the common carotid on the other side resulted in the death of two of three monkeys, even when the second ligation was done nine to 12 months after the first. About $50 \%$ of animals could not tolerate the ligation of major vessels on one side of the neck. In a group of five monkeys which underwent simultaneous complete bilateral occlusion of both the common carotid and vertebral arteries for 30 minutes, three survived with no permanent neurological sequelae (Donald and White, 1961). To demonstrate the extent of the collateral circulation, injection of a barium-gelatin mixture was done in a sixth similarly prepared animal. The injection was made into the aorta and resulted in complete fill of the cerebral arterial system. Various other species have been studied (Linzell and Waites, 1957; Smith and Adams, 1963) and species differences obviously exist. The conclusion that is evident from this is that bilateral occlusion of both the common carotids and vertebral arteries cannot be relied upon to interrupt completely arterial inflow to the brain, and that this occlusion may be compatible with life.

\section{SUMMARY}

A case of bilateral occlusion of the internal carotid arteries in the carotid siphon, secondary to bipetrous fracture of the cranial base, is reported. Verification was obtained both before and after death. This report is of interest, not only from the point of view of a sequel of basal skull fracture, but as an example of bilateral interruption of internal carotid blood flow with retention of the vertebral-basilar system and collateral circulation. Available experimental animal occlusions are briefly discussed. Sequelae of acute internal carotid occlusions are discussed and the problem of occlusion of major vessels is reviewed.

\section{REFERENCES}

Ameli, N. O., and Ashby, D. W. (1949). Non-traumatic thrombosis of the carotid artery. Lancet, 2, 1078-1082.
Andrell, P. O. (1943). Thrombosis of the internal carotid artery. Acta med. scand., 114, 336-372.

Andreyev, L. A. (1935). Functional changes in the brain of the dog after reduction of cerebral blood supply. Arch. Neurol. Psychiat., 34, 481-507.

Blackwood, W., McMenemey, W. H., Meyer, A., Norman, R. M., and Russell, D. S. (1963). Greenfield's Neuropathology, 2nd ed. Arnold, London.

Boyd, R. J., and Connolly, J. E. (1962). Total cerebral ischemia in the dog. Arch. Surg., 84, 434-438.

Brass, K. (1957). Uber inderekte traumatische Rupturen der Hirnbasisarterien. Frankfurt. Z. Path., 68, 254-260.

Bull, J. W. D., and Schunk, H. (1962). The significance of displacement of the cavernous portion of the internal carotid artery. Brit. J. Radiol., 35, 801-814.

Cooper, A. (1836). Some experiments and observations on tying the carotid and vertebral arteries, and the pneumo-gastric, phrenic, and sympathetic nerves. Guy's Hosp. Rep., 1, 457-475.

Caldwell, H. W., and Hadden, F. C. (1948). Carotid artery thrombosis: Report of eight cases due to trauma. Ann. intern. Med., 28. 1132-1142.

Donald, D. E., and White, R. J. (1961). Temporary bilateralocclusion of the common carotid and vertebral arteries in the monkey at normal body temperature. Neurology (Minneap.), 11, 836-838.

Doniger, D. E. (1963). Bilateral complete carotid and basilar artery occlusion in a patient with minimal deficit. Ibid., 13, 673-678.

Ecker, A. D. (1945). Spasm of the internal carotid artery. J. Neurosurg., 2, 479-484.

Elvidge, A. R.. and Werner, A. (1951). Hemiplegia and thrombosis of the internal carotid system. Arch. Neurol. Psychiat. (Chic.), 66, 752-782.

Fields, W. S., Edwards, W. H., and Crawford, E. S. (1961). Bilateral carotid artery thrombosis. Arch. Neurol. (Chic.), 4, 369-383.

Fotopulos, D. (1962). Über zwei Fälle von traumatisch bedingter Karotisthrombose. Zbl. Neurochir., 22, 216-234.

Frøvig, A. G. (1946). Bilateral obliteration of the common carotid artery. Acta psychiat. (Kbh.), suppl., 39.

Gardner, M. D. (1935). Ligation of carotid and vertebral arteries in monkeys. Proc. Soc. exp. Biol. (N.Y.), 32, 1034-1036.

Gray, H., and Goss, C. M. (1954). The Anatomy of the Human Body, by H. Gray, 26th American ed., edited by C. M. Goss, p. 637 . Lea and Febiger, Philadelphia.

Greco, T. (1935). Le trombosi post-traumatiche della carotide. Arch. ital. Chir., 39, 757-784.

Groch, S. N., Hurwitz, L. J., and McDowell, F. (1960). Bilateral carotid artery occlusive disease. Arch. Neurol. (Chic.), 2. 130-133.

Gurdjian, E. S., and Webster, J. E. (1958). Head Injuries: Mechanisms, Diagnosis, and Management. Little, Brown, Boston and Toronto.

Higazi, I. (1963). Post-traumatic carotid thrombosis. J. Neurosurg., 20, 354-359.

Hockaday, T. D. R. (1959). Traumatic thrombosis of the internal carotid artery. J. Neurol. Neurosurg. Psychiat., 22, 229-231.

Houck, W. S., Jackson, J. R., Odom, G. L., and Young, W. G. (1964). Occlusion of the internal carotid artery in the neck secondary to closed trauma to the head and neck. Ann. Surg., 159, 219-221.

Humphrey, J. G., and Newton, T. H. (1960). Internal carotid artery occlusion in young adults. Brain, 83, 565-578.

Johnson, H. C., and Walker, A. E. (1951). The angiographic diagnosis of spontaneous thrombosis of the internal and common carotid arteries. J. Neurosurg., 8, 631-659.

Kecht, B. (1937). Die Bedeutung der Arteria carotis interna in der Hals-Nasen-Ohrenheilkunde. Arch. Ohr.-Nas.-u. Kehlk. Heilk. $143,3-47$.

Linzell, J. L., and Waites, G. M. H. (1957). The effects of occluding the carotid and vertebral arteries in sheep and goats. J. Physiol. (Lond.), 138, 20P.

Löhr, W. (1936). Hirngefässverletzungen in arteriographischer Darstellung. Zbl. Chir., 63, 2593-2608.

Murphey, F., and Shillito, J. Jr. (1959). Avoidance of false angiographic localization of the site of internal carotid occlusion. $J$. Neurosurg., 16, 24-31.

Murray, D. S. (1957). Post-traumatic thrombosis of the internal carotid and vertebral arteries after non-penetrating injuries of the neck. Brit. J. Surg., 44, 556-561. 
Northcroft, G. B., and Morgan, A. D. (1944). A fatal case of traumatic thrombosis of the internal carotid artery. Ibid., 32, 105-107.

Schneider, R. C., and Lemmen, L. J. (1952). Traumatic internal carotid artery thrombosis secondary to nonpenetrating injuries to the neck. J. Neurosurg., 9, 495-507.

Sedzimir, C. B. (1955). Head injury as a cause of internal carotid thrombosis. I. Neurol. Neurosurg. Psychiat., 18, 293296.
Silverstein, A., and Hollin, S. (1963). Occlusion of the supraclinoid으 portion of the internal carotid artery. Neurology (Minneap.), 13, 679-685.

Smith, M. C., and Adams, J. E. (1963). Occlusion of the blood supply to the brain of the goat. J. Neurosurg., 20, 46-59.

Verbiest, H., and Calliauw, L. (1959). Direct and indirect injuries of the cervical carotid arteries. Folia psychiat. neerl., 62, 371-38260 Verneuil (1872). Thrombose de l'artère carotide. Bull. Acad. Méd. (Paris) 2e sér., 1, 46-56. 